\title{
A gênese do conceito freudiano de inconsciente
}

\author{
Gilberto Gomes \\ Universidade Estadual do Norte Fluminense
}

\begin{abstract}
Resumo
Durante toda sua obra, Freud concebe os processos psíquicos como derivados da atividade do cérebro. Aqui é proposta uma reconstituição dos passos inferenciais (constituindo uma seqüência lógica e não cronológica), possibilitados por essa concepção psiconeural, que levaram (sob a influência dos fatos clínicos) ao conceito psicanalítico de inconsciente. Os processos neurofisiológicos subjacentes ao psíquico devem possuir complexidade suficiente para justificar as propriedades psíquicas conhecidas pela consciência. Para Freud, a consciência é uma espécie de percepção interna de processos psíquicos. Como a consciência não é inerente a esses processos, torna-se natural imaginar que eles possam também ocorrer sem serem percebidos (processos pré-conscientes). O conceito de inconsciente propriamente dito também se mostra tributário de sua concepção psiconeural.

Palavras-chave: freud; metapsicologia; problema mente-cérebro; dualismo; monismo; inconsciente
\end{abstract}

\begin{abstract}
The genesis of the Freudian concept of the unconscious. Along all his works Freud conceives of psychical processes as derived from the activity of the brain. We offer here a reconstruction of the inferential steps (making up a logical and not a chronological sequence), made possible by this psychoneural conception, that have led (under the influence of clinical facts) to the psychoanalytical concept of the unconscious. Neurophysiological processes underlying psychical reality must possess enough complexity to justify the psychical properties known by consciousness. According to Freud, consciousness is a sort of internal perception of psychical processes. As consciousness is not inherent to these processes, it is natural to imagine that they may also occur without being perceived (preconscious processes). The concept of the unconscious properly said also appears as dependent on this psychoneural conception.
\end{abstract}

Keywords: freud; metapsychology; mind-brain problem; dualism; monism; unconscious

$\mathrm{E}$ $\mathrm{m}$ trabalho anterior, mostramos que, ao contrário do que muitas vezes se pensa, Freud sempre manteve a concepção de que os processos psíquicos dependem do funcionamento do cérebro (Gomes, 2005). Citações cobrindo toda sua obra (Freud, 1888/1966a; 1891/1957a; 1950/1987; 1900/1982a; 1905/1953b; 1905/1960; 1914/1946; 1915/1982b; 1915/1982c; $1917 / 1957 b ; 1920 / 1955 ; 1930 / 1994 ; 1938 / 1941)$ mostram que Freud sempre considerou a atividade psíquica como tendo fundamento nos processos neurofisiológicos do cérebro.1

Discutimos também as conseqüências desta concepção do psíquico como fundamentado num substrato neurofisiológico. Em primeiro lugar, destacamos a adesão ao pensamento causal em que esta posição implica. Inegavelmente, a pressuposição do determinismo psíquico é um dos componentes essenciais da teoria freudiana. Em segundo lugar, lembramos o aspecto quantitativo presente em todos os aspectos de sua teoria, e que decorre diretamente da suposição de um fundamento material dos processos mentais. Finalmente, a suposição de que o sistema nervoso é responsável pela atividade anímica leva naturalmente à concepção de um aparelho psíquico com extensão espacial, originando o ponto de vista tópico da teoria psicanalítica (Gomes, 2005).

No presente trabalho, discutiremos o papel específico dessa concepção sobre a relação mente-cérebro no desenvolvimento do conceito freudiano de inconsciente. Num momento de grande desenvolvimento das neurociências e de questionamento sobre as relações entre neurociências e psicanálise, evidencia-se a relevância da questão proposta.

\section{O inconsciente na neurofisiologia do século XIX}

A criação por Freud de uma teoria do inconsciente é muitas vezes vista como uma ruptura em relação às tentativas de sua época de explicar os fenômenos psíquicos pelo funcionamento do cérebro. Marcel Gauchet, em seu livro L'inconscient cérébral (1992), opera uma modificação completa desse quadro. Ele mostra como a neurofisiologia do século XIX tinha de fato aberto o caminho para o conceito freudiano de inconsciente. Isso não quer dizer que este estivesse de alguma forma presente ou 
oculto nas formulações dos neurofisiologistas, como poderiam fazer pensar as propostas menos rigorosas de Lancelot Whyte, em seu livro The unconscious before Freud (1960).

Sem negar a originalidade de Freud, é preciso, entretanto, recolocar a criação da psicanálise em seu contexto histórico. No caso, Gauchet faz uma análise detalhada de todo um setor desse contexto histórico, há muito tempo esquecido ou ignorado: o das discussões dos neurofisiologistas e neurologistas da época sobre o inconsciente, concebido ainda sob a perspectiva da teoria dos reflexos, mas tendo, de qualquer forma, o efeito de quebrar muito efetivamente a concepção tradicional do papel central da consciência e da vontade consciente. Não era ainda o conceito freudiano que estava presente, mas sim toda uma problemática que estava claramente colocada, todo um novo campo do "pensável" que estava aberto, como diz Gauchet.

Desse ponto de vista, podemos encontrar um sentido no fato de a psicanálise não ter sido criada por um psicólogo ou um filósofo, mas sim por um neurologista. Evidentemente, essa problemática neurofisiológica do "inconsciente cerebral" não foi o único fator que propiciou a criação do conceito psicanalítico de inconsciente. A questão clínica das neuroses, já bem distinguidas dos outros quadros clínicos de que os neurologistas deviam cuidar, os problemas do hipnotismo, a teoria da evolução, na biologia, todos esses fatores, como mostra Gauchet, foram vetores cuja convergência constituiu uma "encruzilhada" múltipla no universo cultural da segunda metade do século XIX, criando as condições de emergência do conceito freudiano. ${ }^{2}$

Também de especial interesse para compreender a importância do pensamento neurológico e neurofisiológico na formação de Freud é o pouco divulgado livro de Peter Amacher, Freud's neurological education and its influence on psychoanalytic theory (1965). Nele, podemos ver claramente como autores como Brücke, Meynert e Exner, que foram professores de Freud, pensavam questões muito próximas às que moldaram o pensamento desse último.

\section{Conseqüências da concepção psiconeural}

A busca de entender os fenômenos psíquicos como derivados da atividade cerebral, entretanto, pode levar a diferentes tipos de conseqüências na elaboração de uma teoria explicativa. O notável em Freud é que sua crença nessa base fisiológica dos fenômenos psíquicos não o conduziu a aplicar, a estes, os conceitos da fisiologia - como todos aqueles que, no século XIX, construíram suas teorias do "inconsciente cerebral" sobre o modelo do reflexo (Gauchet, 1992). Muito ao contrário, é sua "neurofisiologia" que vai incorporar os conceitos do psíquico, como representação, desejo, afeto, prazer, angústia, pensamento, etc. Isto já aparece muito claramente no Projeto, de 1895. Mais tarde, ele abandonou as hipóteses específicas sobre os mecanismos neurais. Mas o que está presente desde o início até o fim é a idéia de que os processos neurais de base (quaisquer que sejam) devem comportar toda a riqueza dos processos psíquicos.

Para reflexologistas reducionistas como Maudsley ou Setchênov, a concepção neural do psíquico levou à eliminação da vontade consciente e à substituição dos princípios explicativos derivados da consciência de si e dos outros pelos princípios explicativos da fisiologia (reflexo, excitação, inibição, etc.).
Para outros, como Pflüger ou Lewes, a unidade psiconeural terá como conseqüência uma extensão das qualidades da consciência (sensibilidade e vontade) aos próprios reflexos (Gauchet, 1992). Para Freud, ela levou à possibilidade de pensar uma vontade inconsciente, representações inconscientes, pensamentos, desejos e conflitos inconscientes.

\section{Passos inferenciais para a elaboração do conceito freudiano de inconsciente}

Confrontando a teoria freudiana do inconsciente com sua concepção sobre a relação mente-cérebro, podemos reconstituir os seguintes passos inferenciais como etapas lógicas que levaram - em colaboração com outros fatores, sem dúvida - ao conceito freudiano de inconsciente:

Primeiro passo. Se os fenômenos psíquicos conscientes têm um substrato neural, os processos neurais que constituem esse substrato devem ter as características dos fenômenos psíquicos (isto é, características que lhes permitam ser considerados como representações, desejos, afetos, pensamentos, etc.).

Segundo passo. Se existem processos neurais que funcionam como os processos psíquicos de que temos consciência, pode então haver processos neurais que funcionam da mesma maneira, mas sem consciência (pensamentos, desejos, etc., préconscientes).

Terceiro passo. Se existem processos neurais com todas as características do psíquico consciente menos a consciência, pode então haver outros processos neurais com algumas dessas características (as que permitem caracterizá-los como representações, desejos, pensamentos, lembranças, etc.), mas sem algumas outras (negação lógica, contradição, temporalidade, consideração da realidade, etc.). ${ }^{3}$

Proponho esses passos como uma seqüência lógica subjacente ao desenvolvimento do conceito freudiano, e não como uma sucessão de formulações que o autor deveria ter enunciado explicitamente e cronologicamente. Não pretendo, além disso, que o conceito psicanalítico de inconsciente seja o simples resultado de uma inferência lógica a partir de certos pressupostos. É claro que ele resultou também de questões clínicas e teóricas com as quais Freud achava-se confrontado. O que pretendo mostrar é como a resposta que deu a essas questões foi atingida por um caminho que necessitou dessas pressuposições.

\section{Processos neurais com características de processos psíquicos}

Antes de tudo, o que importa constatar é que a suposição de processos neurais possuidores das características dos processos psíquicos foi a condição para formular a hipótese de um inconsciente que é verdadeiramente psíquico, e não simplesmente reflexo, como o proposto por outros autores. Por outro lado, como ele é concebido como constituído por processos naturais, isso permite considerá-lo como dependente de mecanismos causais que podem ir além daquilo que se costumava atribuir aos processos psíquicos, a partir do conhecimento destes pela consciência. Sem essa pressuposição de processos neurais com características psíquicas, o inconsciente se mostraria ou desprovido das características dos fenômenos psíquicos, ou tão dependente dessas que seria impossível concebê-lo como consti- 
tuído por processos naturais. Mais ainda, e principalmente, essa dependência das características dos fenômenos psíquicos, tais como se mostram à nossa consciência, impediria a concepção de processos inconscientes possuidores de algumas, mas não de outras, dessas características, o que caracteriza, precisamente, os processos do sistema do inconsciente propostos, de forma inovadora, pela teoria psicanalítica.

Outros autores podiam, com maior facilidade, colocar uma seqüência inconsciente de reflexos no lugar de um pensamento consciente, do que imaginar um pensamento (propriamente dito) como realidade neural. Ora, o substrato neural de um pensamento consciente, para Freud, não é uma seqüência de reflexos, mas sim, como podemos constatar com especial clareza no Projeto de uma psicologia, um verdadeiro pensamento neural (voltarei a esse ponto na próxima seção).

Vários autores já haviam proposto a idéia de processos fisiológicos possuidores de características do psíquico. Em alguns, como Pflüger, Lewes, Hering (citados por Gauchet, 1992), ou Butler (1880/1920), a extensão de atributos psíquicos aos reflexos fisiológicos ou até mesmo à matéria inanimada levava, entretanto, a uma perda de especificidade do psíquico. Dizer que os reflexos medulares têm características adaptativas que manifestam uma sensibilidade e uma vontade é, sem dúvida, propor um "psíquico" inconsciente, mas não concorre muito com a concepção de um inconsciente verdadeiramente psíquico, quer dizer, de um domínio novo que esteja ao mesmo tempo fora do campo dos reflexos e fora do que mostra a consciência. $\mathrm{O}$ mesmo se aplica a dizer, com Hering e Butler, que a memória é uma característica de toda a matéria.

Ainda outros autores, admitindo a identificação do psíquico à atividade cerebral, se voltaram para a psicologia associativa para dar conta desse psíquico, pois essa forma de psicologia era certamente a que melhor se adaptava a uma identificação com os processos neurofisiológicos conhecidos na época, isto é, com os reflexos. Assim, Meynert (que foi professor de Freud), por exemplo, escrevia em 1884:

Imaginemos que o córtex é uma tabula rasa, e apresentemos a ele um fenômeno que (...) estimula duas áreas distintas do córtex (...) as duas imagens registradas se associam e, sempre que uma delas é re-excitada, a excitação vai se estender através das fibras associativas para as outras células (...). (Meynert, citado por Amacher, 1965, p. 27)

Como observa Amacher (1965, p. 28), a psicologia associacionista tendia a eliminar as faculdades psicológicas, como a razão, a vontade, etc., reduzindo os processos psíquicos à combinação de sensações. ${ }^{4}$ Pode-se constatar que o próprio Freud, em algumas passagens, rende homenagem ao associacionismo, mas sem jamais limitar os processos psíquicos a associações entre sensações.

Ao contrário desses autores, Freud supôs a existência de um campo próprio de processos neurais possuindo plenamente as características do psíquico. Quando digo que Freud postulou a existência de processos fisiológicos possuidores das características do psíquico, isso não implica necessariamente na suposição de um isomorfismo entre processos fisiológicos e a aparência que têm os fenômenos psíquicos para a consciência. Podemos, é verdade, ver uma busca de tal isomorfismo na tentativa de construção teórica do Projeto. Por outro lado, essa posição já havia sido criticada pelo próprio autor, em sua monografia sobre as afasias: "Uma tal transposição [seria] é, claro, totalmente injustificada. As propriedades dessa modificação [fisiológica, produzida por uma excitação], devem ser definidas por elas mesmas e independentemente de seu correlato psicológico" (Freud, 1891/1983, pp. 105-106)..

Seja como for, o importante é que, na elaboração do Projeto, o que Freud requer dos processos neurais responsáveis pela atividade psíquica é um grau de complexidade, uma estrutura e uma direcionalidade que sejam suficientes para dar conta de processos como o desejo, o pensamento, a atenção, os afetos, etc., sem pretender reduzi-los a meros processos de associações de sensações.

\section{O desejo e o pensamento na neuropsicologia hipotética do Projeto}

O primeiro passo inferencial descrito acima pode ser ilustrado pelas hipóteses sobre o desejo e sobre o pensamento presentes no Projeto. ${ }^{5} \mathrm{O}$ desejo supõe uma associação complexa entre: (1) enchimento dos neurônios do núcleo do sistema psicológico, a partir da fonte pulsional, e sua descarga por ocasião da vivência de satisfação; (2) investimento dos neurônios responsáveis pela percepção (e pela lembrança) do objeto presente no momento dessa vivência; (3) investimento dos neurônios responsáveis pela percepção (e pela lembrança) do movimento reflexo que permitiu a suspensão do estímulo endógeno (Freud, 1950/1987, p. 410412, 414-415). Um novo estado de tensão pulsional produzirá não somente o investimento da representação do objeto, mas também um esforço para percebê-lo (pp. 332-333).

Temos, assim, os equivalentes fisiológicos de todos os elementos exigidos por sua concepção psicológica do desejo: a representação do objeto desejado, a tendência a se aproximar dele, a exigência de percebê-lo e a representação da atividade que pode trazer o prazer previsto. Ele não fica reduzido a uma simples associação de sensações.

Freud também apresenta, no Projeto, toda uma teoria neurofisiológica do pensamento, que evocaremos muito brevemente. O desejo provoca o investimento de uma representação de objeto, mas esse investimento se faz com uma quantidade menor, que não leva à alucinação (Freud, 1950/1987, pp. 421, 429). Essa redução quantitativa é o resultado de uma inibição efetuada pelo eu (Ich), concebido como um grupo de neurônios constantemente investido (p. 416). Se o investimento de desejo corresponde ao investimento dos neurônios $a+b$ e o investimento perceptivo ao investimento dos neurônios $a+c$, o pensamento será o processo que buscará um caminho que leve de $c$ a $b(\mathrm{p}$. 423). Esse caminho será determinado não somente pelas facilitações, mas também pela representação-alvo (Ziel) (p. 424). O neurônio $b$, que corresponde a esse alvo, exerce uma atração sobre o deslocamento da quantidade.

Percebemos que o autor imagina um processo neural que seja o equivalente do fato psicológico de que nosso pensamento prático é guiado por um alvo. Não se dispunha ainda do conceito sistêmico de processos teleonômicos, mas vemos que a limitação de evitar a todo custo um pensamento teleológico em relação aos fenômenos naturais não vale para Freud. Algumas vezes, 
será mesmo preciso ir contra as facilitações presentes (Freud, 1950/1987, p. 424-425) e é o eu que tornará isso possível (p. 429). Verificamos que não são simples reflexos ou associações que vêm tomar o lugar do pensamento. Ao contrário, Freud se esforça para construir um modelo neural do pensamento que possa representar as características psicológicas do próprio pensamento (tal como ele nos é dado a conhecer pela consciência, mas nem por isso limitando-o ao que essa revela).

\section{O papel da consciência nos processos psíquicos}

É preciso considerar também qual é a teoria freudiana da consciência. Isso importa, aqui, pois o problema mente-cérebro é antes de tudo o problema mente consciente-cérebro (Gomes, 1995). É só secundariamente que se coloca o problema da relação entre o psíquico inconsciente e o cérebro. Duas concepções sobre a consciência podem ser opostas. Uma considera que a qualidade da consciência é intrínseca a todos os processos psíquicos. Mesmo se restringirmos essa tese a uma parte somente dos processos psíquicos, o importante aqui é ser a consciência considerada por esse ponto de vista como intrínseca a eles. A outra concepção considera que a consciência é um evento mental distinto, que tem certos processos psíquicos como seu objeto. É, portanto, uma propriedade relacional (pois envolve a relação entre dois estados mentais) e não uma propriedade intrínseca (Rosenthal, 1986; Gomes, 1995). Esta segunda concepção é sem dúvida a de Freud (Gomes, 2003).

a consciência (...) é excitável (...) a partir (...) do sistema da percepção, em primeira linha; e em seguida, a partir das excitações de prazer e desprazer (...) Mas (...) a consciência (...) tornou-se também um órgão sensorial para uma parte de nossos processos do pensamento. (Freud, 1900/1982a, p. 547).

Rosenthal (1986, p. 339) observa que essa concepção não implica necessariamente numa teoria materialista do psíquico. Mas ela se adapta bem à tese da identidade psiconeural, ou dos dois aspectos.

Se queremos de fato estimar o papel da concepção de Freud sobre a relação mente-cérebro na gênese do conceito psicanalítico de inconsciente, devemos relacionar essa concepção com sua teoria da consciência. Se a consciência inclui a percepção de processos psíquicos, que correspondem a processos neurofisiológicos, então esses processos neurofisiológicos devem poder dar conta da complexidade dos processos psíquicos percebidos pela consciência. Isso quer dizer que categorias psicológicas derivadas da consciência de si mesmo (desejo, afeto, pensamento, etc.) devem ser, numa certa medida, aceitas e não consideradas como puramente ilusórias; e que se deve supor que os processos neurofisiológicos que são seu fundamento devam possuir mecanismos de uma complexidade suficiente para justificá-las, mesmo se essa complexidade ultrapassa largamente o que é conhecido pela neurofisiologia de seu tempo. (Primeiro passo inferencial descrito acima).

Como a consciência não é uma qualidade inerente aos processos psíquicos que são conscientes, mas sim uma percepção desses processos, torna-se natural imaginar que os processos percebidos pela consciência possam também ocorrer sem serem percebidos. ${ }^{6}$ A consciência torna-se, assim, contingente, e será possível falar em representações, pensamentos e desejos não conscientes. Como, nessa etapa, são pensados processos não conscientes que têm as mesmas propriedades dos processos conscientes, temos aqui os processos chamados por Freud de pré-conscientes. (Segundo passo inferencial).

Pode-se perceber aqui que a concepção psiconeural não é de todo indispensável a esse segundo passo inferencial, que pode ser justificado unicamente pela teoria da consciência. Todavia, essa concepção o torna mais fácil de realizar.

Em relação a esse segundo passo, podemos relembrar esta passagem do Projeto:

Tratamos os processos psíquicos como algo que poderia dispensar esse conhecimento pela consciência, algo que existe independentemente dela. Estamos preparados para descobrir que algumas de nossas suposições não são confirmadas pela consciência. Se não nos deixarmos cair em erro nisso, eis o que se segue à pressuposição de que a consciência não dá um conhecimento completo nem digno de confiança sobre os processos neuronais: esses processos devem ser considerados, de início e em toda sua extensão, como inconscientes, e devem ser inferidos como outras coisas naturais. (Freud, 1950/1987, p. 400).

Isso quer dizer que mesmo os processos psíquicos que são objeto da consciência são concebidos como tendo uma natureza que não é nem completamente nem certamente conhecida pela consciência.

James Strachey acrescenta uma nota, no ponto correspondente da Standard Edition (Freud, 1950/1966b, p. 308), dizendo que a última afirmação da passagem citada refere-se a "entidades fisiológicas" e que será preciso um certo tempo para que o autor possa repeti-la, em A interpretação dos sonhos (1900/1982a, p. 580), em relação a "eventos psíquicos". Ora, fica claro que é uma concepção dualista que impede Strachey de ver que Freud já fala, aqui, de eventos psíquicos - lembremos o início da própria passagem citada: "Tratamos os processos psíquicos...". Podemos lembrar, também, que, em outra passagem do Projeto (Freud, 1950/1987, pp. 403-404), ele escreve: "processo anímico fisiológico" ("physiologischer Seelenvorgang") ${ }^{7}$ - o que para outros seria uma contradictio in adjecto.

Vimos que a concepção psiconeural não é, em realidade, indispensável ao segundo passo inferencial, se bem que o torne mais natural. É preciso, entretanto, que os processos não conscientes aos quais chegamos sejam pensados em termos de seu substrato neural para poder aceder ao terceiro passo. Para essa terceira etapa lógica, assim como para a primeira, essa concepção será fundamental. É a possibilidade de pensar os processos psíquicos em termos de algo que não é puramente psíquico, mas também fisiológico, que dará a Freud a liberdade de pensar a possibilidade de processos psíquicos que, além do fato de não serem conscientes, não têm todas as características dos fenômenos psíquicos aos quais estamos habituados. Processos que, ao contrário, têm propriedades bem diferentes, mesmo conservando a característica de serem psíquicos, ou seja, não se reduzindo aos simples mecanismos reflexos da neurofisiologia de sua época. O fato de que esta era insuficiente para suas necessidades o obrigou a inventar uma neurofisiologia (o Projeto) que muitos podem qualificar como ficcional. Mas a distância 
dessa teoria em relação à neurofisiologia propriamente dita não deveria nos impedir de constatar que seu criador não poderia ter dispensado a formulação neural para desenvolver os conceitos que desenvolveu.

\section{Conclusão}

Podemos verificar que essa formulação neural não foi uma simples linguagem metafórica, uma simples roupagem da teoria, um simples resíduo de hábitos de pensamento anteriores, como muitas vezes se considera, mas, na verdade, a condição de possibilidade de pensar os processos do inconsciente. $\mathrm{O}$ conjunto de pressupostos teóricos e metateóricos presentes no Projeto constituíram a incubadora na qual pôde ser gestada a teoria psicanalítica.

Depois, o autor pôde deixar de lado as hipóteses específicas sobre os mecanismos neurofisiológicos responsáveis pelos processos psíquicos, que desenvolveu nessa obra, por ele repudiada. Manteve, entretanto, a maioria das hipóteses que aí propôs sobre a natureza desses processos, postulando mecanismos de um aparelho psíquico teórico não referido a mecanismos neurofisiológicos específicos. Nem por isso abandonou a concepção de um fundamento natural e neural - embora aberto às influências culturais - desse aparelho (Gomes, 2005). Pretendo ter demonstrado que, sem essa concepção neural, não teria sido possível para Freud criar e desenvolver sua teoria do inconsciente.

\section{Referências}

AAmacher, P. (1965). Freud's neurological education and its influence on psychoanalytic theory. Psychological Issues, IV, 4. Nova York: International Universities Press.

Butler, S. (1920). Unconscious memory. Londres: Jonathan Cape. (Texto original publicado em 1880)

Freud, S. (1941). Abriss der Psychoanalyse. In Gesammelte Werke, vol. 17 (pp. 65-147). Frankfurt am Main: Fischer. (Texto original publicado em 1938)

Freud, S. (1946). Zur Einführung des Narzissmus. In Gesammelte Werke, vol. 10 (pp. 137-170). Frankfurt am Main: Fischer. (Texto original publicado em 1914)

Freud, S. (1953a). The interpretation of dreams. In Standard Edition, vol. 5 (pp.
339-751). Londres: Hogarth. (Texto original publicado em 1900)

Freud, S. (1953b). Three essays on the Theory of Sexuality. In Standard Edition, vol. 7 (pp. 123-243). Londres: Hogarth. (Texto original publicado em 1905)

Freud, S. (1955). Beyond the pleasure principle. In Standard Edition, vol. 18 (pp. 7-64). Londres: Hogarth. (Texto original publicado em 1920)

Freud, S. (1957a). Appendix B. In Standard Edition, vol. 14 (pp. 206-208). Londres: Hogarth. (Texto original publicado em 1891)

Freud, S. (1957b). Mourning and melancholia. In Standard Edition, vol. 14 (pp. 243-258). Londres: Hogarth. (Texto original publicado em 1917)

Freud, S. (1960). Jokes and their relation to the unconscious. In Standard Edition, vol. 8 (pp. 1-258). Londres: Hogarth. (Texto original publicado em 1905)

Freud, S. (1966a). Preface to the Translation of Bernheim's 'Suggestion'. In Standard Edition, vol. 1 (pp. 21-22). Londres: Hogarth. (Texto original publicado em 1888)

Freud, S. (1966b). Project for a scientific psychology. In Standard Edition, vol. 1 (pp. 281-387). Londres: Hogarth. (Texto original publicado em 1950)

Freud, S. (1982a) Die Traumdeutung. In Studienausgabe, vol. 2 (pp. 488-588). Frankfurt am Main: Fischer. (Texto original publicado em 1900)

Freud, S. (1982b). Triebe und Triebschicksale. In Studienausgabe, vol. 3 (pp. 75 102). Frankfurt am Main: Fischer. (Texto original publicado em 1915)

Freud, S. (1982c) Das Unbewusste. In Studienausgabe, vol. 3 (pp. 119-162). Frankfurt am Main: Fischer. (Texto original publicado em 1915)

Freud, S. (1983). Contribution à la conception des aphasies. Paris: Presses Universitaires de France. (Texto original publicado em 1891)

Freud, S. (1987). Entwurf einer Psychologie. In Gesammelte Werke, Nachtragsband (pp. 373-486). Frankfurt am Main: Fischer. (Texto original publicado em 1950)

Freud, S. (1994). Le malaise dans la culture. In Oeuvres complètes: Psychanalyse vol. 18 (pp. 245-333). Paris: Presses Universitaires de France. (Texto original publicado em 1930)

Gauchet, M. (1992). L'Inconscient cérébral. Paris: Seuil.

Gomes, G. (1995). Self-awareness and the mind-brain problem. Philosophical Psychology, 8(2), 155-165.

Gomes, G. (2003). A teoria freudiana da consciência. Psicologia: Teoria e Pesquisa, 19(2), 117-125.

Gomes, G. (2005). O problema mente-cérebro em Freud. Psicologia: Teoria e Pesquisa, 21(2), 149-155.

Rosenthal, D. M. (1986). Two concepts of consciousness. Philosophical Studies, 49, 329-359.

Whyte, L. L. (1960). The unconscious before Freud. Nova York: Basic Books. 
${ }^{1}$ As passagens relevantes, traduzidas, encontram-se em Gomes, 2005. No presente artigo, as referências a Freud foram feitas pela fonte utilizada em cada caso, dando-se preferência à referência ao original quando este foi confrontado com as traduções disponíveis. Em alguns casos, em que nem todas as citações foram confrontadas ao original, ou quando foi feita referência a uma nota do tradutor, tanto a tradução quanto o original foram listados, sendo a referência específica à fonte utilizada no caso. As citações literais foram traduzidas para o português pelo autor. Adotamos a convenção de indicar a obra pelo ano da publicação original seguido pelo da publicação consultada.

${ }^{2}$ A esses fatores poderíamos ainda acrescentar a considerável atenção dada por autores do século XIX à explicação psicológica ou neurofisiológica dos sonhos. Veja-se a este respeito os numerosos trabalhos, publicados no período de 1800 a 1890, que são citados por Freud (1900/1953a) no primeiro capítulo (ou só na bibliografia) de A Interpretação dos Sonhos.

${ }^{3}$ A ausência de negação lógica, de contradição, de temporalidade e de consideração da realidade, nos processos do inconsciente propriamente dito, é discutida na parte 5 de O Inconsciente (Freud, 1915/1982c).

${ }^{4}$ Mesmo assim, no que diz respeito a Meynert, observemos que o conceito de representação-alvo, que terá um importante papel na teoria freudiana (Freud, 1900/1982a, capítulo 7, parte E), já está presente nesse autor (citado por Amacher, 1965, p. 39).

${ }^{5}$ Este trabalho, publicado pela primeira vez em 1950 (onze anos após a morte do autor), foi redigido em 1895.

${ }^{6}$ Um processo consciente, para Freud, é um processo psíquico que é percebido pela consciência. Esta não é, portanto, algo inerente ao próprio processo, mas algo que se acrescenta a ele.

${ }^{7}$ Lembremos que o autor usa Seele e Psyche, e seelischer e psychischer, respectivamente, como sinônimos (podendo ser traduzidos como alma e psique, e anímico e psíquico, respectivamente).

Gilberto Gomes, doutor em Psicopatologia Fundamental e Psicanálise pela Université Paris VII (França), é professor associado no Laboratório de Cognição e Linguagem, Universidade Estadual do Norte Fluminense. Endereço para correspondência: Av. Alberto Lamego, 2000; Campos, RJ; CEP 28013-602. Tel./fax: (22) 2726-1589. E-mail: ggomes@uenf.br 